\title{
EFFECTS OF CURRENCY FLUCTUATION AND HERDING BEHAVIOR ON EMERGENCE OF BULL AND BEAR MARKETS IN TEHRAN STOCK EXCHANVE
}

\author{
Samira Abbasi Shehni ${ }^{1}$
}

\begin{abstract}
This study analyzed the effects of currency fluctuations and herding behavior of investors on the emergence of bull and bear markets in 36 industries listed in the Tehran Stock Exchange. The Christie-Huang model (1995) and the Kalman filter were employed to evaluate herding behavior and currency shock, respectively, in order to detect the days on which these fluctuations acted as anomalous pulses. In addition, the logistic regression was utilized to analyze and predict bull and bear markets because the dependent variable was dichotomous. According to the results, herding behavior had no effects on the market trend and emergence of bull and bear markets; however, currency fluctuations showed very slight effects.
\end{abstract}

Keywords: currency fluctuation, herding behavior, bull market, bear market

\section{Statement of the Problem}

Considering the recent everincreasing advances in financial markets, behavioral finance has attracted many researchers stating that personal and psychological characteristics affect financial decisions. It also states that various events and incidents affect financial markets in addition to the mass and emotional behavior of investors (Chiang Li, 2005).

Introduced into financial markets for a few decades, behavioral finance analyzes the behavior of investors and tries to identify and perceive their reactions accurately. Hence, it analyzes external and internal factors affecting the emergence of bull and bear markets and leading to people's herding behavior, resulting in their emotional processes of making sales and purchases. 
Currency fluctuations refer to the volatility of currency exchange rates, a situation that can also be called currency turbulence or currency crisis. In fact, it is an economic variable, closely related to financial markets and basically in line with inflation. The volatility of currency exchange rates affects the share price by changing the value of business assets. Currency fluctuation is not a new phenomenon in economy because many cases of this incident have occurred in both Iranian and global economies. The volatility of currency exchange rate has generally been in line with inflation and price rises, although it has not followed a steady and balanced trend because of sudden and unpredicted rises and reductions. Accordingly, many economists believe that what leaves negative effects on economy is not the increased currency exchange rate but sudden increases or decreases in currency exchange rate (Zareh H. \& Rezaei Z., 2006).

In the behavioral finance paradigm, herding is considered a case of behavioral bias which can significantly affect the performance of capital markets. Recently, herding has dramatically emerged as one of the major setbacks of capital markets, inasmuch as markets have been so deprived of analysis that there is no difference in what share is purchased and whether all shares and groups become simultaneously negative or positive. Herding behavior indicates a human's tendency to act like others. When a mass society performs a particular action or shows a particular reaction, it is subjectively difficult for other people to act in the opposite direction of the mass. In other words, herding behavior refers to the behavior shown by a group of people who act similarly. In fact, there is a correlated behavioral pattern among people (Chiang Li, 2005).

Herding behavior has also been defined as accepting high risks without having sufficient information, something that can be interpreted as the obvious intention of some investors to copy and follow the behavior of other investors. Herding behavior is the most public phenomenon known in financial markets within the framework of psychology. This phenomenon can provoke illogical reactions shown by investors (Izadinia, 2007).

Herding behavior is actually the emotional behavior of investors in 
specific events. According to a market analysis, the investors of the Tehran Stock Exchange are no exception. Sales and purchasing lines are formed because of emotional and herding behavior shown by people who enter the market late because they are not willing to take risks. Intending to gain more profit, then they enter the market at the wrong time so as not to fall behind. Finally, they make hasty decisions to make sales or purchases with the most insufficient information (Yousefi, 2009).

\section{Purchase-encouraging and} sale-encouraging markets are colloquially described as bull and bear markets, respectively. In fact, they describe the general trend in the capital market. The emphatic assumption regarding the two terms bull market and bear market refers to how these two animals fight because a bull uses its horns to hit and throw up an enemy, whereas a bear uses its claws to hit and knock an enemy down to the ground (Nyberg, 2013).

In a study entitled Market Emotions, Blasco et al. (2012) used daily data to analyze the factors affecting herding behavior in the Spain Stock Exchange between 1997-2003. They
433

realized that herding behavior was influenced by previous returns, investors' emotions and subjectivity, and their imitation tendency.

The goal of this study is to analyze the effects of currency fluctuations and herding behavior on the emergence of bull and bear markets in the Tehran Stock Exchange.

\section{Research Methodology}

This applied study employed the existing documents of the Tehran Stock Exchange to analyze the effects of currency fluctuations and herding behavior of investors on the emergence of bull and bear markets. The research data were monthly collected from the stock market database at www.tse.ir. In fact, the data pertaining to 2011-2015 were used as the research input. This was a prospective study based on objective data.

The Kalman filter - an algorithm using a series of measurements including errors over time to estimate the status of a dynamic system - was employed in Eviews to analyze monthly currency fluctuations in an effort to detect the months in which 
these fluctuations acted as anomalous pulses.

Then the Christie-Huang model (1995) was utilized to determine the herding behavior by calculating the cross-sectional standard deviation (CSSD) of returns in the Tehran Stock Exchange.

$$
\operatorname{CSSD}_{t}=\sqrt[2]{\frac{\sum_{i=1}^{N_{t}}\left(R_{i, t}-R_{m, t}\right)^{2}}{N_{t}-1}}
$$

$N_{t}$ : the number of companies analyzed at $t$

$R_{i, t}:$ returns of Company $i$ at $t$

$R_{m, t}:$ market return

Chang, Cheng and Khorana (2000) extended this method and used a nonlinear model focusing on the crosssectional absolute deviation (CSAD):

$$
\operatorname{CSAD}_{t}=\frac{1}{N_{t}} \sum_{i=1}^{N_{t}}\left|R_{i, t}-R_{m, t}\right|
$$

The quality of being a bull or bear market is evaluated in the following way. $P_{t}$ is the price of entering the market at $t\left(P_{t}<(>) P_{t} 1_{-}^{+} ; \mathrm{i}=1, \ldots, \mathrm{L} ; \mathrm{L}\right.$ is the magnitude of financial capacity). In this case, a rise occurs at $t$.

Given the identification of rises and reductions, the rise-to-reduction (or reduction-to-rise) periods are defined as bear (or bull) markets with $D_{t}=1\left(D_{t}=0\right)$, which is a binary variable (Nyberg, 2013).

Since the dependent variable was dichotomous, the binomial logistic regression (binary) was employed to make predictions. Dichotomy means the occurrence of a random incident in two possible situations. In fact, the logistic regression predicts a probability ranging between 0 and 1 . The regression coefficients of the logistic regression equation provide specific information on the chance of each specific case to join the zero group or the one group.

The following equation was employed to make estimations in Eviews 9: 


$$
\mathrm{Y}=\alpha+\beta_{1} X_{1}+\beta_{2} X_{2}+e
$$

\section{Research Variables}

$Y$ : the dependent variable stating the quality of being a bull or bear market (in the form of a virtual variable)

$\boldsymbol{X}_{\boldsymbol{I}}$ : herding behavior

$X_{2}$ : currency fluctuation

$\boldsymbol{e}$ : error component

\section{Data Analysis}

The collected data were processed to lay the foundations for the analysis of the interplay between data to test the research hypotheses. The regression was estimated in Eviews 3, and then specific tests were conducted to analyze the hypotheses. Finally, the estimation results were taken into account to draw conclusions and interpret the research hypotheses.

\section{Research Data}

The necessary data included currency exchange rates, code 1 indicating bull markets, code 0 indicating bear markets, and data showing investors' herding behavior. These data were collected daily from the stock market database at www.tse.ir, $\underline{\text { www.cbi.ir, and other databases such as }}$ www.estjt.ir and www.banksepah.ir. The collected data, used as the research inputs, pertained to years 2014-2016. It was impossible to extract documented data pertaining to currency exchange rates before November 23, 2014, the date from which all the research data were collected for the necessity of historical conformity.

Regarding the data pertaining to bull and bear markets, the returns on market daily indices were calculated on specific dates once the closing prices of market indices were obtained. Then the moving average was obtained in a fiveday span. According to the linear diagram of moving averages, the significant range was determined between -0.004 and +0.004 after performing several calculations and trial-and-error processes with different values. Then it was formulated by using the if function in Excel. Therefore, if the moving average of returns on the closing market index exceeds +0.004 , then it is a bull market shown by 1 ; otherwise, if the moving average is below -0.004 , then it is a bear market shown by 0 . 
The designated currency was the dollar. After extracting the currency exchange rate on the research dates in the market, the currency fluctuations were determined in Eviews 3 through the Kalman filter used as a very efficient turning method. There are basically two major advantages to the use of this filter. First, it helps monitor unobservable variables (trend and rotation) because it is used in the economic literature topics including logical expectations, missing
436

observations, the permanent consumption income theory, unobservable elements in business intervals, and the natural unemployment rate. Second, they can be estimated to observe them and see the trend diagram.

According to Figure (1), the trend of fluctuations was obtained through the Kalman filter after entering currency fluctuation variables. Then the diagram was drawn.

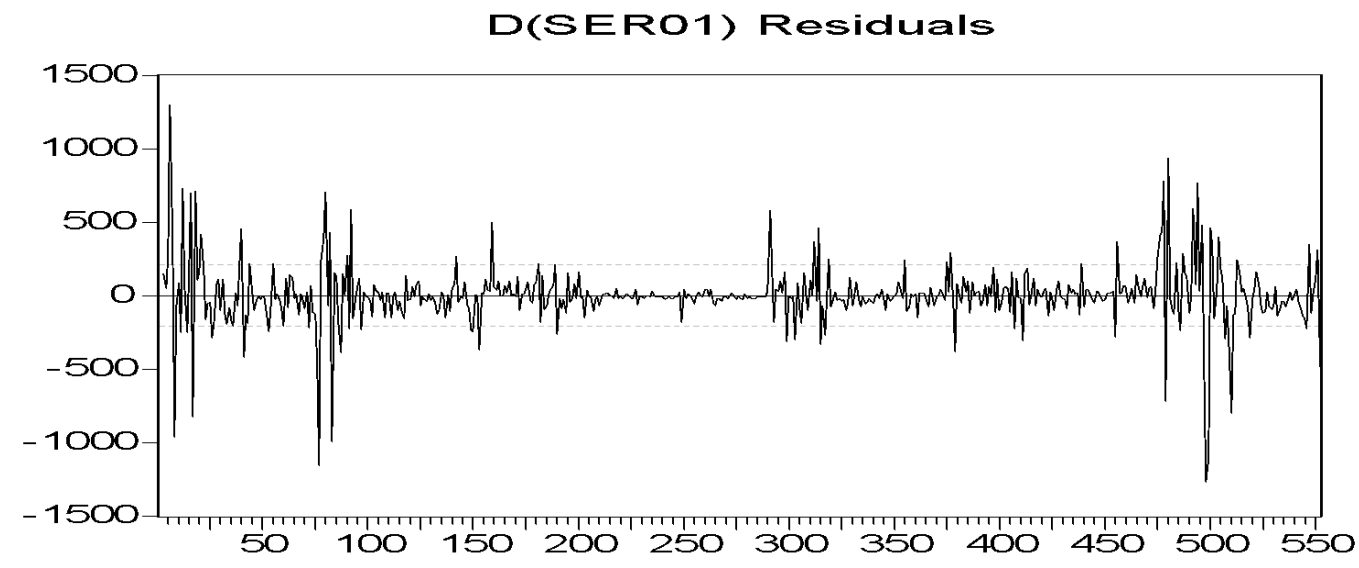

Figure (1). Currency Exchange Rate Fluctuations (Source: Eviews)

The third series of data pertained to herding behavior, determined through the Christie-Huang formula for 36 out of 39 industries listed in the Tehran Stock Exchange. For this purpose, the total indices of industries were extracted for the designated dates. Then their daily returns were calculated and put into the Christie-Huang formula to determine the herding intensity, shown by Figure (2). 


$$
C \operatorname{SSD}_{t}=\sqrt[2]{\frac{\sum_{i=1}^{N_{t}}\left(R_{i t}-R_{m t}\right)^{2}}{N_{t}-1}}
$$

Figure (2): Herding Behavior

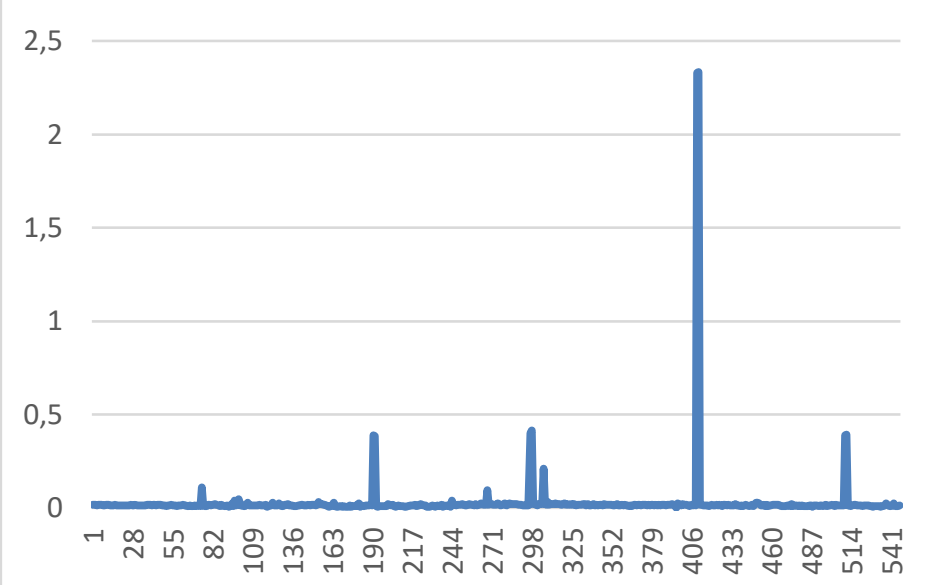

Estimation of Data and Interpretation of Results

To estimate the logit model, a work file was first created in Eviews to enter variables. Then the research data, including dependent and independent variables, were inserted into the file.

The final estimation included the variable, coefficient, standard error of regression coefficients (Std. Error), zstatistic, and relevant probability (Prob.) or the p-value. In addition, RE is the dependent variable pertaining to the quality of being a bull or a bear market (shown by 1 or 0 ). The independent variables included HE (herding behavior) and SH (currency exchange rate fluctuations). If the $\mathrm{p}$-value of a test is below 0.10 , then it is significant.

The logistic regression was employed to make regression estimations with 1-5 interrupts in the significant range in order to test the research hypotheses. Figure (3) shows the market trend variables. 
Periódico do Núcleo de Estudos e Pesquisas sobre Gênero e Direito

Centro de Ciências Jurídicas - Universidade Federal da Paraíba

V. 9 - $\mathrm{N}^{\mathrm{o}} 02$ - Ano 2020

ISSN | 2179-7137 | http://periodicos.ufpb.br/ojs2/index.php/ged/index

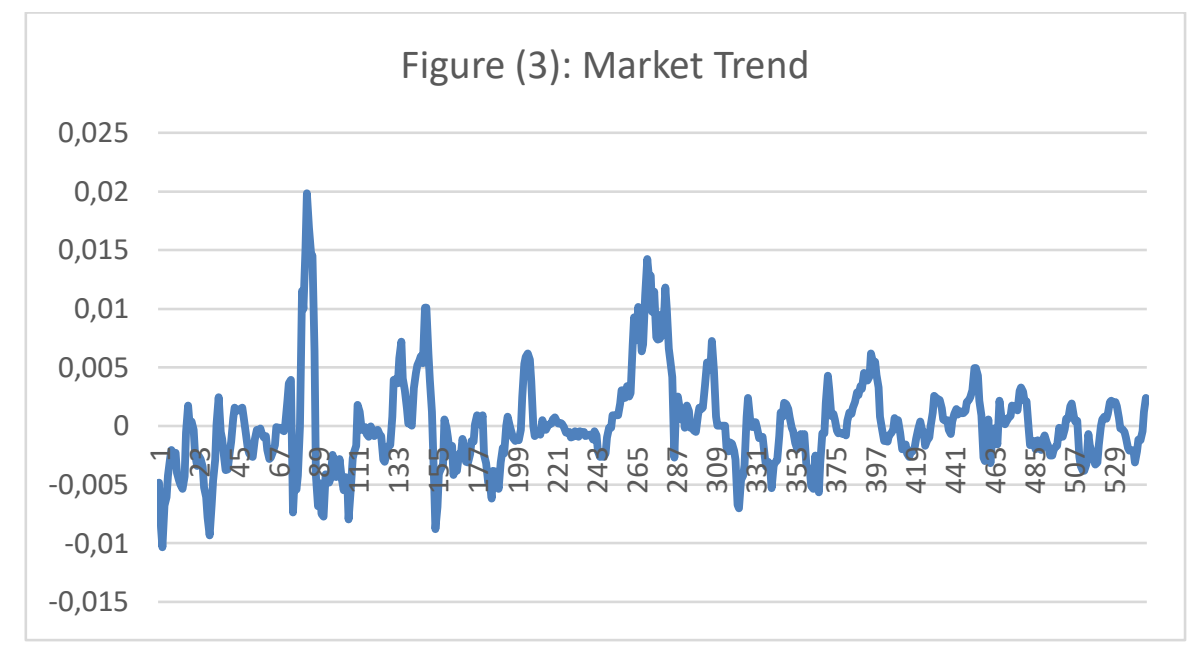

Table (1) shows an overview of

the results of calculating estimations at

different levels.

Table (1). An Overview of P-Values Pertaining to the Significant Probability Range

S

\begin{tabular}{|c|}
\hline nif \\
\hline
\end{tabular}

Probability

Range

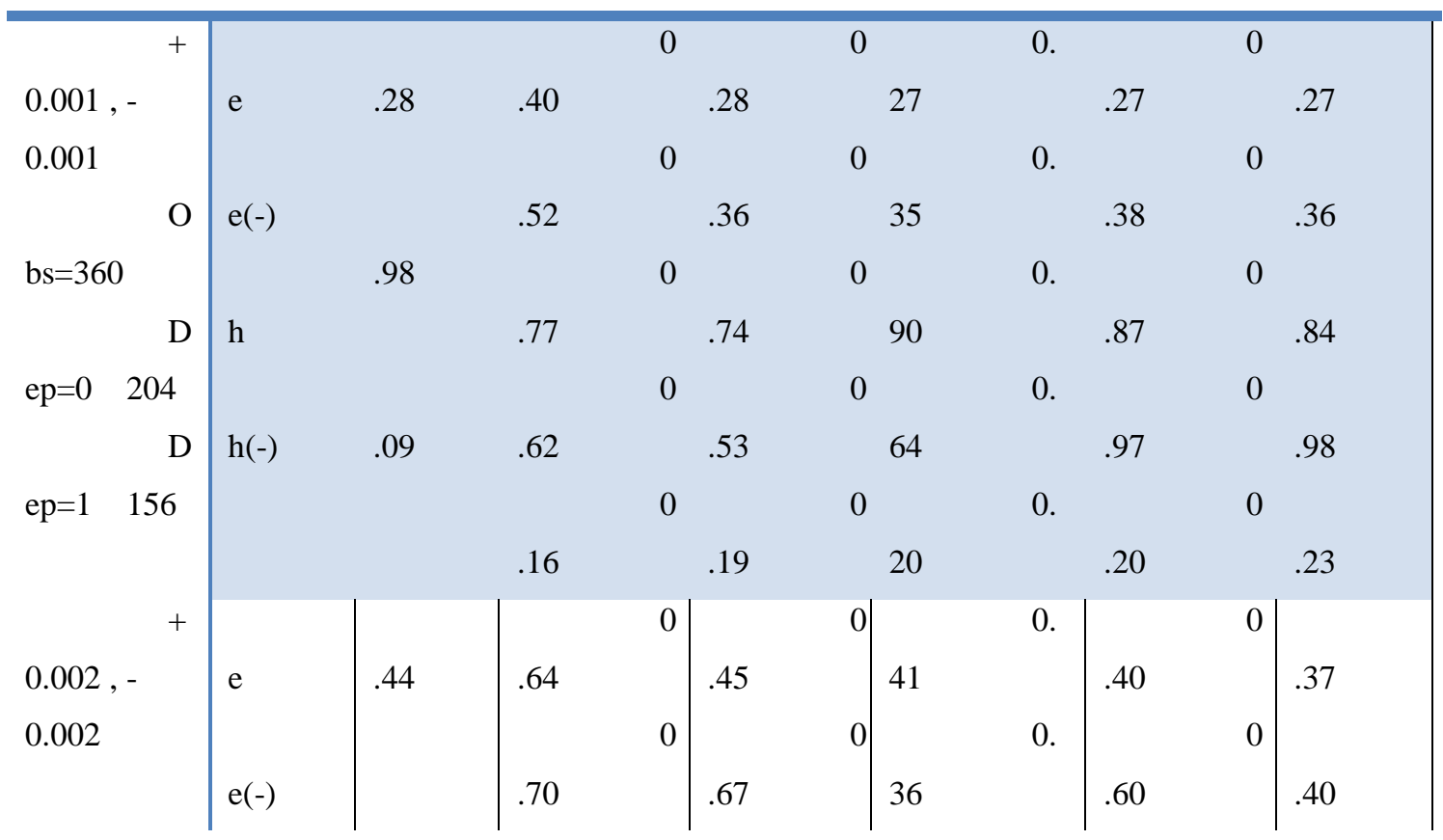


Periódico do Núcleo de Estudos e Pesquisas sobre Gênero e Direito

Centro de Ciências Jurídicas - Universidade Federal da Paraíba

V. 9 - $\mathrm{N}^{\circ} 02$ - Ano 2020

ISSN | 2179-7137 | http://periodicos.ufpb.br/ojs2/index.php/ged/index

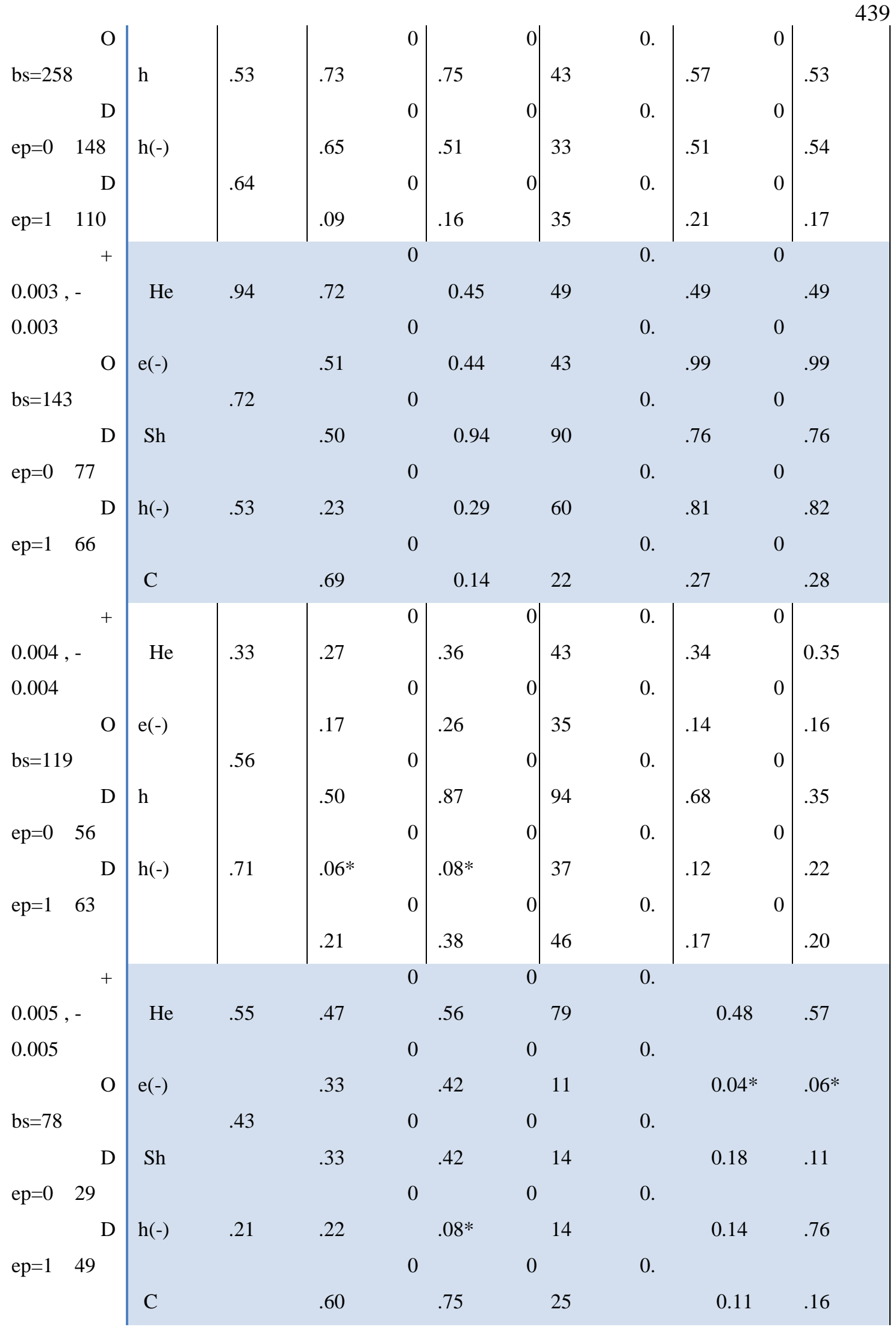


Obs: number of observations; dep: quality of being a bull or a bear market; he: herding behavior variable; ()he: herding behavior variable with an interval; sh: currency fluctuations variable; (-)sh: currency fluctuations variable with an interval; c: constant coefficient; prob: probability (Source: Research Findings)

Since the test $p$-value is considered lower than 0.10 in Table (1), numbers with $*$ are significant at the relevant intervals; however, the $[-0.004$, $+0.004]$ is a more logical range because the number of observations decreased within $[-0.005,+0.005]$. With the regression estimation, coefficients were significant for currency fluctuations in 1day and 2-day intervals.

\section{The first research hypothesis is as} follows:

Currency fluctuations affected the emergence of bull and bear markets (in a case study conducted on 36 industries listed in the Tehran Stock Exchange).

$\mathrm{H}_{0}$ : Currency fluctuations had no effects on the market trend.
$\mathrm{H}_{1}$ :

Currency fluctuations affected the market trend.

Given the significance level of these intervals $(<\% 10)$, the null hypothesis was rejected; therefore, the test was significant. As a result, currency fluctuations affected the emergence of bull and bear markets.

\section{The second research hypothesis is as} follows:

The herding behavior of investors affected the emergence of bull and bear markets (in a case study conducted on 36 industries listed in the Tehran Stock Exchange).

$\mathrm{H}_{0}$ : Herding behavior had no effects on the market trend.

$\mathrm{H}_{1}$ :

Herding behavior affected the market trend.

Given the significance level of these intervals $(<\% 10)$ than which the coefficients were greater, the test was not significant. Therefore, the hypothesis was not rejected, and herding behavior 
had no effects on the emergence of bull

and bear markets.

Table 2. Regression Estimation:

Dependent Variable: RE

Method: ML - Binary Logit

Date: 09/05/17 Time: 10:08

Sample(adjusted): 1454

Included observations: 119

Excluded observations: 335 after adjusting endpoints

Convergence achieved after 7 iterations

Covariance matrix computed using second derivatives

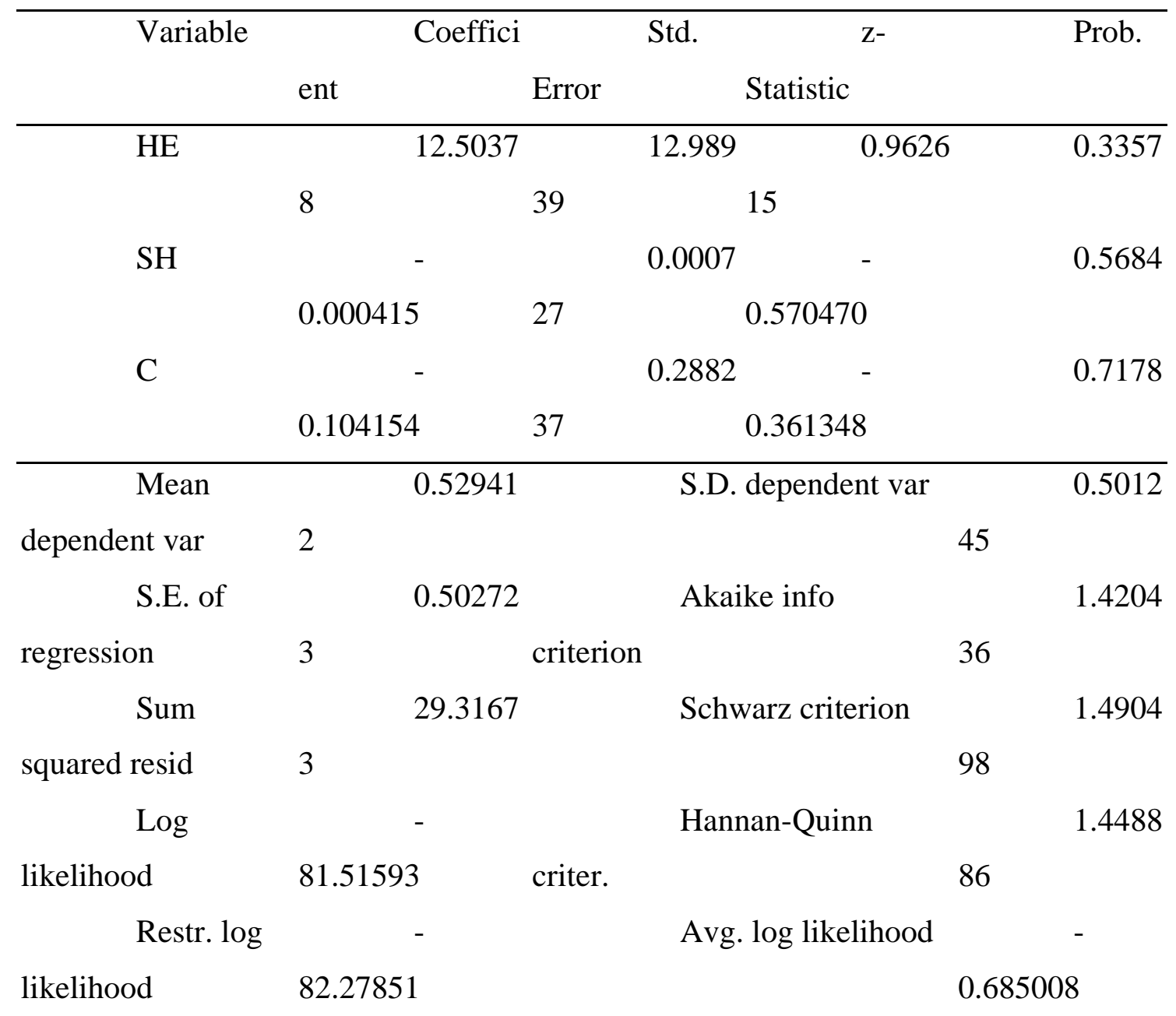




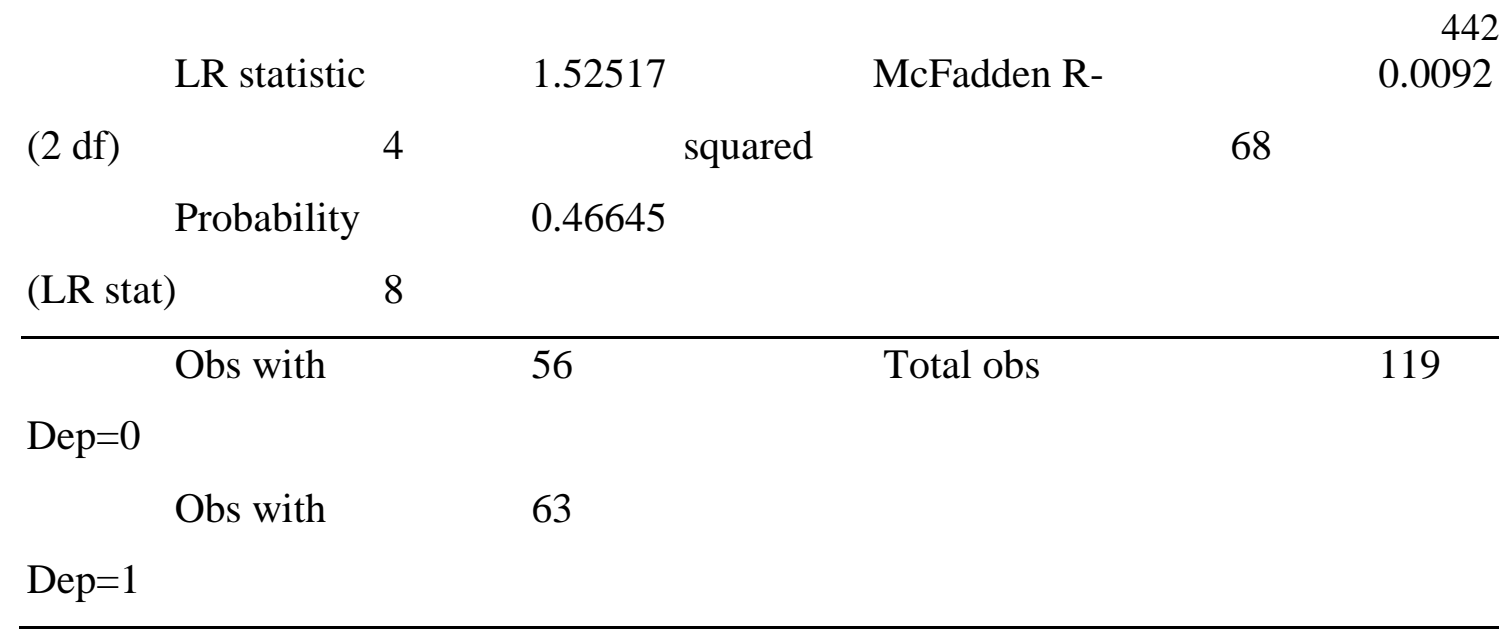

Table 3. One-Day Interval Estimation

Dependent Variable: RE

Method: ML - Binary Logit

Sample(adjusted): 2454

Included observations: 118

Excluded observations: 335 after adjusting endpoints

Convergence achieved after 8 iterations

Covariance matrix computed using second derivatives

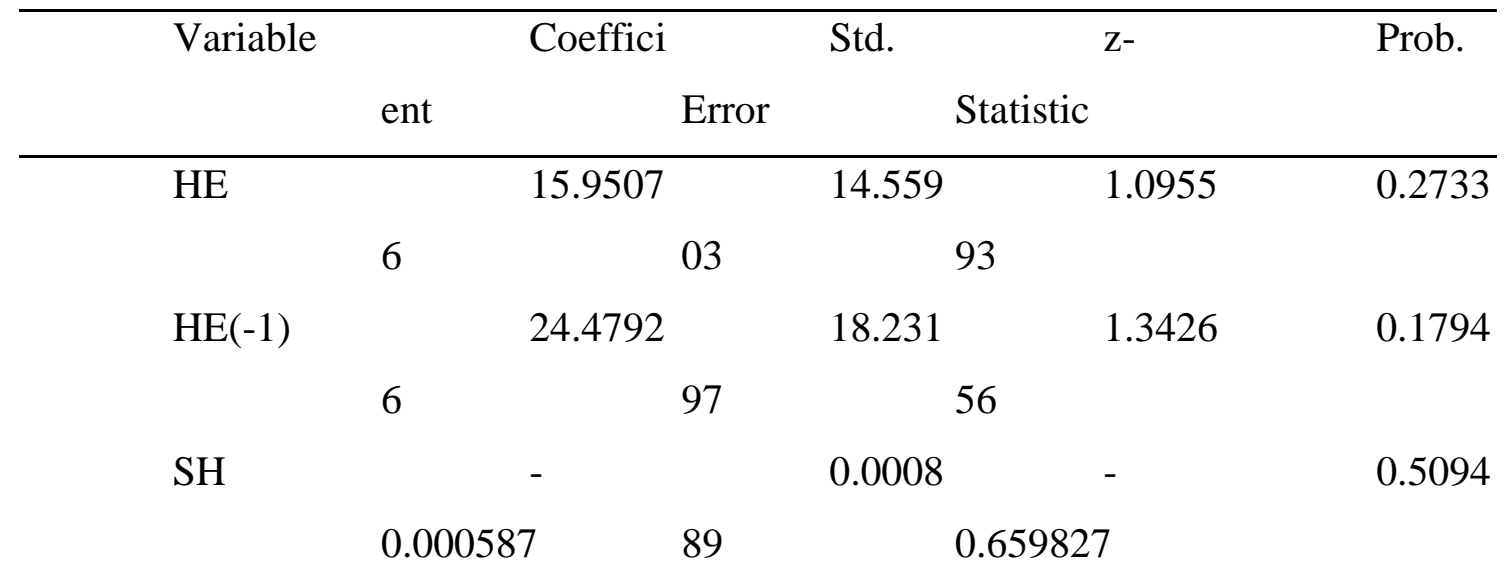




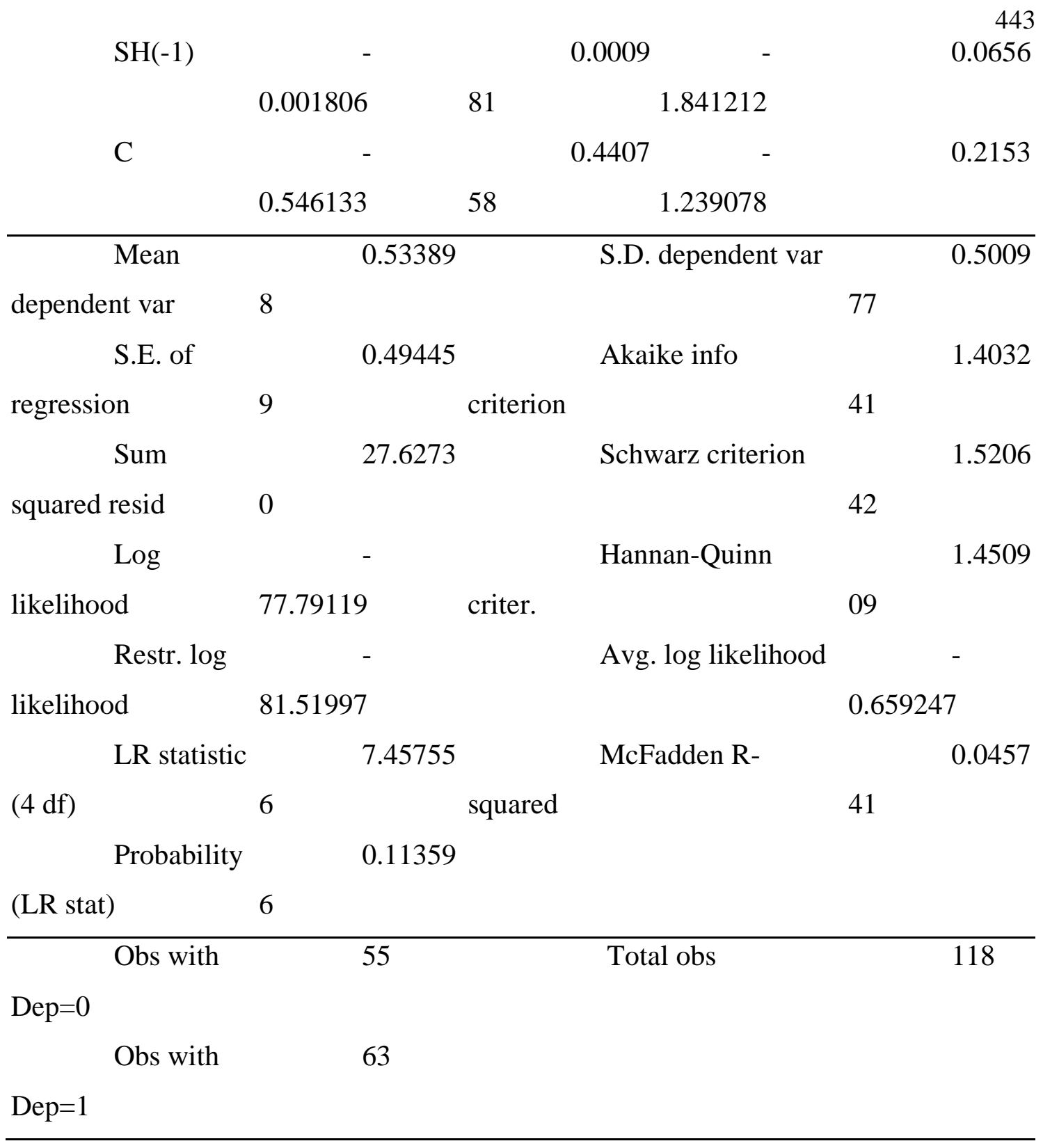

Table 4. Two-Day Interval Estimation

Dependent Variable: RE

Method: ML - Binary Logit 
Date: 09/05/17 Time: 10:21

Sample(adjusted): 3454

Included observations: 117

Excluded observations: 335 after adjusting endpoints

Convergence achieved after 8 iterations

Covariance matrix computed using second derivatives

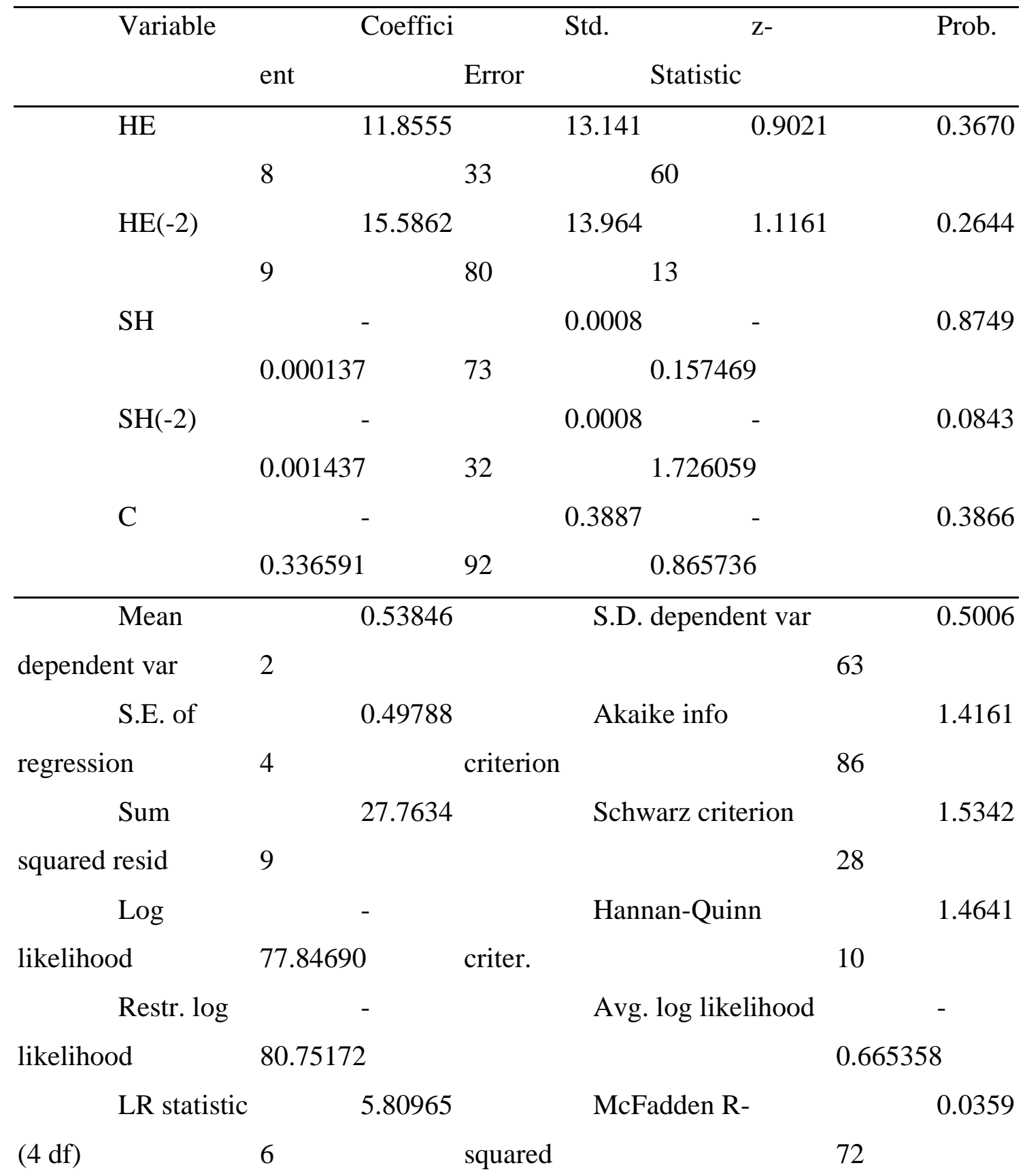


Probability $\quad 0.21382$

(LR stat) $\quad 1$

$\begin{array}{llll}\text { Obs with } & 54 & \text { Total obs } & 117\end{array}$

Dep $=0$

Obs with

Dep $=1$

Then the final model was

estimated at the designated intervals with

respect to the significance of $\mathrm{p}$-values.

Table 5. Final Model

Dependent Variable: RE

Method: ML - Binary Logit

Date: 09/06/17 Time: 13:52

Sample(adjusted): 3454

Included observations: 117

Excluded observations: 335 after adjusting endpoints

Convergence achieved after 8 iterations

Covariance matrix computed using second derivatives

\begin{tabular}{|c|c|c|c|c|c|}
\hline \multirow[t]{2}{*}{ Variable } & \multicolumn{2}{|c|}{ Coeffici } & \multirow[t]{2}{*}{ Std. } & \multirow[b]{2}{*}{ Statistic } & \multirow[t]{2}{*}{ Prob. } \\
\hline & ent & Error & & & \\
\hline \multirow[t]{2}{*}{$\mathrm{HE}$} & & & 15.059 & 1.0711 & 0.2841 \\
\hline & 0 & 59 & & 84 & \\
\hline \multirow[t]{2}{*}{$\mathrm{SH}$} & - & & 0.0009 & - & 0.6223 \\
\hline & 0.000455 & 24 & & 0.492562 & \\
\hline \multirow[t]{2}{*}{$\mathrm{SH}(-1)$} & - & & 0.0009 & - & 0.1033 \\
\hline & 0.001623 & 96 & & 1.628906 & \\
\hline
\end{tabular}




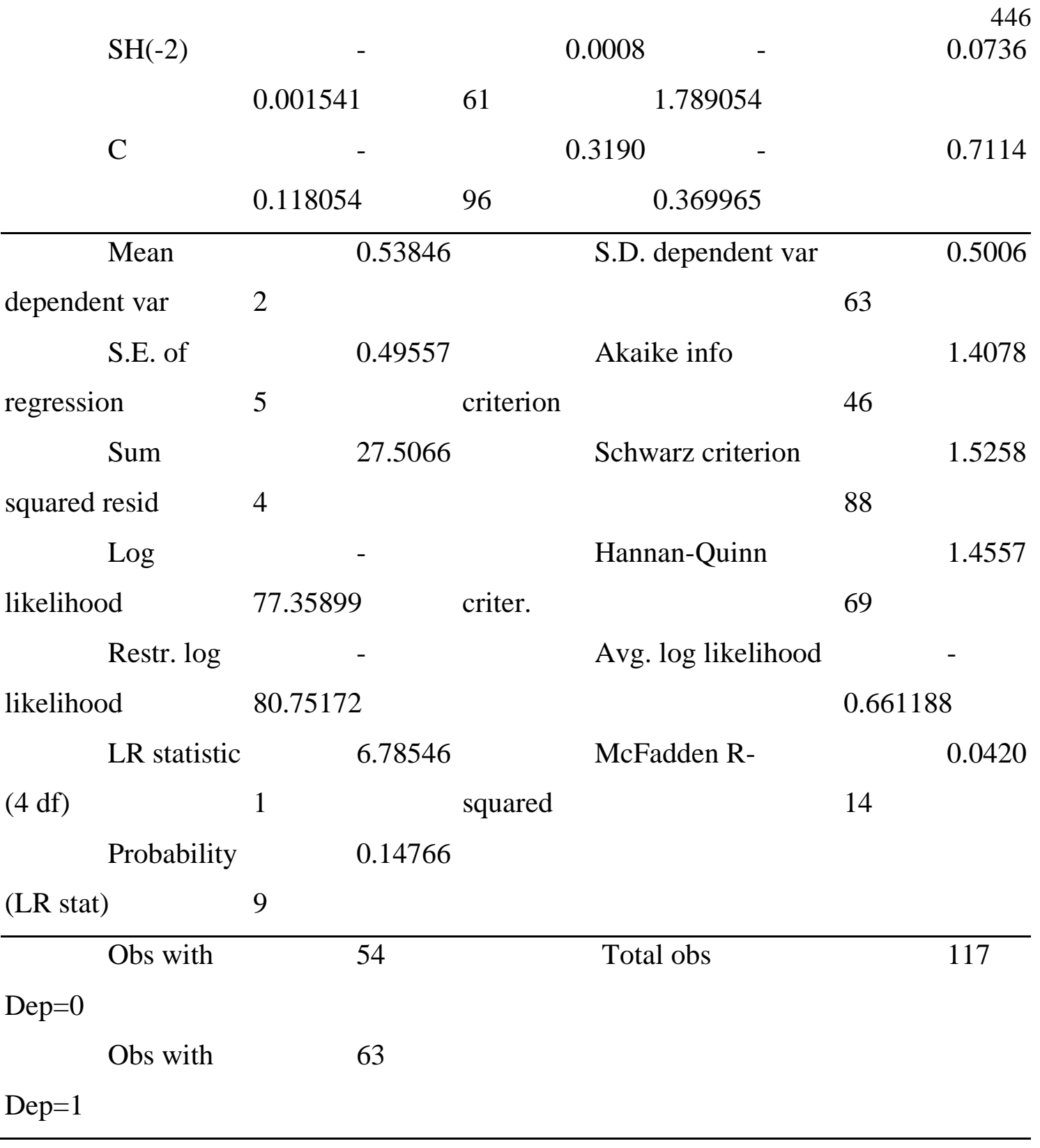

Since prob $=0.07$ of the two-day interrupt, pertaining to currency fluctuations, is smaller than 0.10 in comparison with prob $=0.10$ of the oneday interval, it is more significant; thus, $\mathrm{H}_{0}$ is rejected. In other words, the coefficient is statistically valid. In this estimation, the Mc Fadden R-squared statistic indicates $\% 4.2$ of goodness of fit in the model regression and explanatory power. Regarding the logistic regression model, it is similar to $\mathrm{R}^{2}$ in the ordinary regression. In fact, it ranges between 0 and 1 and measures the goodness of fit. The closer this index to 1 , the more the 
model matches reality, and the higher the goodness of fit, and vice versa.

The total regression significance was analyzed at the $\% 90$ confidence level along with the accuracy of model explicitness with the LR statistic. Finally, two independent variables were employed in two significant ranges for the dependent variable with five interrupts after testing different combinations to delete the herding behavior variable from the model.

After selecting the optimal model, the coefficients were presented:

Table 6. Model Coefficients

\begin{tabular}{|c|c|c|c|c|}
\hline $\begin{array}{l}\text { Pro } \\
\\
\quad b\end{array}$ & $\begin{array}{l}\text { Z- } \\
\text { Statistic }\end{array}$ & $\begin{array}{l}\text { Std } \\
\text { Error. }\end{array}$ & $\begin{array}{r}\text { Coeffici } \\
\text { ent }\end{array}$ & $\begin{array}{r}\text { Varia } \\
\text { ble }\end{array}$ \\
\hline $\begin{array}{l}0.28 \\
\quad 41\end{array}$ & $\begin{array}{l}1.071 \\
184\end{array}$ & 15.05 & $\begin{array}{r}16.1316 \\
0\end{array}$ & $\mathrm{HE}$ \\
\hline $\begin{array}{l}0.62 \\
23\end{array}$ & $\begin{array}{l}- \\
0.492562\end{array}$ & $\begin{array}{l}0.000 \\
924\end{array}$ & $\begin{array}{l}- \\
0.000455\end{array}$ & SH \\
\hline $\begin{array}{r}0.10 \\
\\
\\
\end{array}$ & $\begin{array}{l}- \\
1.628906\end{array}$ & $\begin{array}{r}0.000 \\
996\end{array}$ & $\begin{array}{l}- \\
0.001623\end{array}$ & $-1) \mathrm{SH}$ \\
\hline $\begin{array}{ll}0.07 & \\
& 36\end{array}$ & $\begin{array}{l}- \\
1.789054\end{array}$ & $\begin{array}{l}0.000 \\
861\end{array}$ & $\begin{array}{l}- \\
0.001541\end{array}$ & $-2) \mathrm{SH}$ \\
\hline $\begin{array}{ll}0.71 & \\
& 14\end{array}$ & $\begin{array}{l}- \\
0.369965\end{array}$ & $\begin{array}{r}0.319 \\
096\end{array}$ & $\begin{array}{l}- \\
0.118054\end{array}$ & $\mathrm{C}$ \\
\hline
\end{tabular}

(Source: Research Findings)

The final analysis of variables indicates that currency fluctuations had slightly negative effects on the emergence of bull and bear markets; however, the herding behavior had no effects on the market trend.

Table 7. Final Effects of Variables 


\begin{tabular}{|c|c|}
\hline $\mathrm{R} 1=$ he & 6.09855882998 \\
\hline $\mathrm{R} 2=\mathrm{sh}$ & -0.000172005729714 \\
\hline$(-1) \mathrm{R} 3=\mathrm{sh}$ & -0.00091347795352 \\
\hline$(-2) \mathrm{R} 4=\mathrm{sh}$ & -0.000582546850796 \\
\hline $\mathrm{R} 5=\mathrm{c}$ & -0.0446305279158 \\
\hline
\end{tabular}

(Source: Research Findings)

Analyzing the Results of Testing the

\section{First Hypothesis}

The first sub-hypothesis:

Currency fluctuations affected the emergence of bull and bear markets (in a case study conducted on 36 industries listed in the Tehran Stock Exchange).

At the significance level ranging from $0.0055_{-}^{+}$to $0.001{ }_{-}^{+}$, the tested hypothesis for the prob values of research findings indicated that one-day and two-day intervals were significant at the $\% 90$ confidence level. Therefore, the null hypothesis was rejected, something which indicated that currency fluctuations affected the emergence of bull and bear markets.

\section{Analyzing the Results of Testing the}

\section{Second Hypothesis}

The second sub-hypothesis:

The herding behavior of investors affected the emergence of bull and bear markets (in a case study conducted on 36 industries listed in the Tehran Stock Exchange).

At the significance level ranging from $0.005_{-}^{+}$to $0.001_{-}^{+}$, the tested hypothesis for the prob values of research findings indicated that one-tofive-day intervals were not significant at the $\% 90$ confidence level. Therefore, the null hypothesis was not rejected, something which indicated that the herding behavior had no effects on the emergence of bull and bear markets.

\section{References}

Blasco, N. Corredor, P. Fereruela. (2012)." Does herding affect volatility? implications for the Spanish stock market", Quantitative Finance Journal, $12(2), 311-327$. 
Chien.Chiang Lee, (2005). Energy

consumption \& GDP in developing countries: A cointegrated panel analysis, Energy Economics, Elsevier, 27(3), 415427, May.

Henry, Nyberg. (2013). "Predicting bear and bull stock markets with dynamic binary time series models", Banking \& Finance Journal, 3351-3363.

Izadinia, N. and Hajian, A. (2009). "Analyzing and testing the herding behavior in the industries listed in the Tehran Stock Exchange". Stock Exchange Quarterly, 2(7): 105-132.

Yousefi, R. (2009). "Investigating and testing the herding behavior of investors in Stock Exchange". Journal of Development and Evolution Management, 2(5): 57-64.

Zareh, H. and Rezaei, Z. (2006). "Effects of currency, coin, and housing market on the Tehran Stock Exchange trend: vector error correction model". Journal of Human Science Research (University of Isfahan), 21(2): 99-112 